\title{
Retrospective Study of Tuberculosis in the Province of Kenitra (Morocco)
}

\author{
Bouhaddioui Bouchra1*, Brik Kamal', Hassouni Taoufik², Ayoub Fouad ${ }^{3}$, Bejja Fadia4, \\ Bengueddour Rachid ${ }^{5}$
}

\footnotetext{
${ }^{1}$ Regional Center of the Trades of the Education and Training, Department of Life Sciences and Earth, Kenitra, Morocco ${ }^{2}$ Regional Center of the Trades of the Education and Training, Department of Life Sciences and Earth, Meknes, Morocco ${ }^{3}$ Regional Center of the Trades of the Education and Training, Department of Informatics, Kenitra, Morocco ${ }^{4}$ Service Networks of Health Institutions, hospital Idrissi, Kenitra, Morocco ${ }^{5}$ Laboratory of Biology and Health, Department of Biology, University Ibn Tofail, Kenitra, Morocco Email: ${ }^{\star d r}$ _bouchra2010@yahoo.fr
}

How to cite this paper: Bouchra, B., Kamal, B., Taoufik, H., Fouad, A., Fadia, B. and Rachid, B. (2020) Retrospective Study of Tuberculosis in the Province of Kenitra (Morocco). Advances in Infectious Diseases, 10, 181-187.

https://doi.org/10.4236/aid.2020.104016

Received: June 25, 2020

Accepted: September 21, 2020

Published: September 24, 2020

Copyright $\odot 2020$ by author(s) and Scientific Research Publishing Inc. This work is licensed under the Creative Commons Attribution International License (CC BY 4.0).

http://creativecommons.org/licenses/by/4.0/

(c) (i) Open Access

\begin{abstract}
Tuberculosis is a ubiquitous and contagious infectious disease caused by $\mathrm{Myco}$ bacterium tuberculosis (Koch's bacillus). Morocco considers tuberculosis a strategic priority, mobilizing human and material resources to fight it. The objective was to describe the distribution of the disease socio-economic and geographic factors in the province of Kenitra. This was a transverse descriptive retrospective study of 1005 cases of intra- and extra-pulmonary tuberculosis carried out from January 1, 2017, to December 31, 2017, in tuberculosis and respiratory disease screening and treatment center. This study was based on the use of the files of tuberculosis patients who were diagnosed and treated at the center. The parameters studied are age, sex, municipality and place of residence. Genexpert techniques to differentiate between positive and negative microscopic tuberculosis were used. The results showed that the average age of Tuberculosis patients is 36.95 years, the minimum age is 12 months, and the oldest is 87 years old. The $30-44$ age group is the most affected by $42 \%$, followed by that of 15 - 29 years (29\%), the oldest 75 - 90 are the least affected. The survey also revealed that men and Inactive people are more affected by the disease with infection rates of $60.95 \%$ and $39 \%$ respectively, followed by women $38.8 \%$, the employees (35\%), then students $16 \%$. In rural areas, we recorded a rate of $58.26 \%$ ahead of cities $41.73 \%$. This study has shown that the determinants of tuberculosis are manifold and relate mainly to unfavorable socioeconomic conditions, linked to poverty, population growth, human migration, which explains the incidence of the disease from the point of socio-economic view.
\end{abstract}

\section{Keywords}

Tuberculosis, Risk Factors, Kenitra, Morocco 


\section{Introduction}

Tuberculosis (TB) is a ubiquitous infectious disease caused by bacilli of the $M y$ cobacterium Tuberculosis complex, also known as Koch's bacillus. It is mainly transmitted by air. Humans are the only reservoir of disease that is transmitted from an affected subject to an uninjured subject. The path of acquisition of bacilli can be digestive from milk from sick farm animals. Despite the different tuberculosis control strategies, tuberculosis is still a major public health problem worldwide. A third of the world's population is infected with Bacillus de Koch [1].

Recent studies have estimated that the determinants of tuberculosis are manifold and relate mainly to the unfavorable socio-economic conditions linked to poverty, population growth, human migration and the HIV/AIDS epidemic, which explains the socio-economic incidence of the disease. In 2015, the World Health Organization (WHO) reported 10.4 million new TB cases; the death rate is increasing in low and middle income countries [2].

In Morocco, despite efforts to fight TB, the frequency of the disease is still considerable and continues to pose a major public health problem; according to the latest WHO estimates, the number of incident cases of tuberculosis was 37,000 for 2015 and 36,000 for 2016, an incidence of 103 new episodes of tuberculosis per 100,000 inhabitants. This shows, on the one hand, the extent of the need for strengthening preventive measures against this infection.

The objective of this study is to describe the epidemiology of tuberculosis in terms of socioeconomic and geographic factors in the province of Kenitra. Finally, this study will represent a development of TB infection according to risk factors to provide a methodology for eradicating the disease.

\section{Material and Methods}

\subsection{Description of the Study}

This was a transverse descriptive retrospective study of 1005 patients diagnosed and treated for intra- and extra-pulmonary tuberculosis carried out from January 1, 2017 to December 31, 2017 in the center for screening and treatment of tuberculosis and respiratory diseases at the Moulay El Hassan dispensary in Kenitra city in Morocco.

The patients in our study followed their treatment at the hospital where the study was performed. The hospital officials provided us with all the information regarding the parameters studied.

The study parameters are age, sex, community and place of residence, the clinical picture at the first consultation specifying the location of the pathology and the result of sputum laboratory examinations according to genexpert techniques to tell the difference between positive and negative microscopic tuberculosis.

\subsection{Statistical Analyzes}

Data entry and analysis was done using Excel software, the purpose of which was 
to highlight the characteristics of the patients. The results are generally expressed as relative frequencies and/or means \pm standard deviation.

\section{Results and Discussion}

During the study period, 1005 files were included, the average age of tuberculosis patients is 36.95 years, the minimum age of patients is 12 months and the oldest patients are 87 years (Table 1 ).

Table 1 shows that the age group $30-44$ is most affected by the disease (42.31\%), followed by the age group $15-29(29.21 \%)$. The oldest individuals (75 - 90) are the least affected. These results are similar to those of the national with a percentage of $63 \%$ of cases [3]. Middle-aged people are most affected by TB because from the age of 30 , they start smoking and frequenting places where the air is polluted such as coffee. Tuberculosis mainly affects adults in their most productive years [4].

The mean age of the set was 37.9 years \pm 18.54 . The majority of TB patients are between the ages of 15 and 44 (65.55\%). By also taking into account the notion of smoking, which is considered a risk factor since it, disturbs the activity of the mucous defenses responsible for controlling bronchial infections [5]. Smoking greatly increases the risk of active TB and death. It is involved in more than $20 \%$ of tuberculosis cases in the world, the higher rate of tuberculosis men compared to those women can also be due to smoking or exposure of the air polluted by tobacco in popular circles [4].

Of the 1005 TB cases, we have 615 males, $60.95 \%$ and 39.05\% females (Table 2 ), with a sex ratio of 1.55 in favor of males, implying that males are most affected by TB because of their occupational activity, and they work the most compared to females. "TB mainly affects women when they are economically productive and of childbearing age" [6]. This result is compatible with the situation in Morocco, since its sex ratio was 1.5 in favor of men [3].

The distribution of patients by age and sex shows that male patients were more affected (60.88\%) than female patients (39.12\%) with a sex ratio of 1.55 in favour of males. The mean age of the group was $37.9 \pm 18.54$ years. The majority of TB patients are between 15 and 44 years of age, 65.55\% (Table 3).

The study also showed that the unemployed were most affected by the disease (38.40\%), followed by functionary and students (Figure 1). This indicates that poverty is one of the factors that affect TB transmission and is directly linked to poor nutrition and poor living conditions (according to WHO). These are the social determinants of health [7].

People living in rural areas are most affected by the disease $(58.26 \%)$ compared to people living in urban areas (41.73\%). This is due to the influence of socio-economic determinants related to large urban areas [4]. Similarly, people living between 1 and 4 people in the same household are most affected by TB with $92 \%$ of cases followed by people living between 5 and 9 people who account 
Table 1. Age distribution of tuberculosis cases.

\begin{tabular}{ccc}
\hline Age & Nb of Infected & Tuberculosis patients rate (\%) \\
\hline $1-14$ & 46 & $4.58 \%$ \\
$15-29$ & 293 & $29.15 \%$ \\
$30-44$ & 425 & $42.29 \%$ \\
$45-59$ & 123 & $12.24 \%$ \\
$60-74$ & 78 & $7.76 \%$ \\
$75-90$ & 40 & $3.98 \%$ \\
\hline
\end{tabular}

Table 2. Distribution of tuberculosis cases by sex.

\begin{tabular}{cc}
\hline Sex & Tuberculosis infection rate \\
\hline Male & $60.95 \%$ \\
Female & $39.05 \%$ \\
\hline
\end{tabular}

Table 3. Distribution of tuberculosis subjects by age and sex.

\begin{tabular}{cccc}
\hline Age & Sex & Infected by sex & Tuberculosis infection rate \\
\hline \multirow{2}{*}{$1-14$} & Male & 28 & $60.9 \%$ \\
& Female & 18 & $39.1 \%$ \\
$15-29$ & Male & 190 & $64.8 \%$ \\
& Female & 103 & $35.2 \%$ \\
$30-44$ & Male & 229 & $53.9 \%$ \\
& Female & 196 & $46.1 \%$ \\
$45-59$ & Male & 74 & $60.2 \%$ \\
& Female & 49 & $39.8 \%$ \\
& Male & 48 & $61.5 \%$ \\
$75-90$ & Female & 30 & $38.5 \%$ \\
& Male & 27 & $67.5 \%$ \\
\hline
\end{tabular}

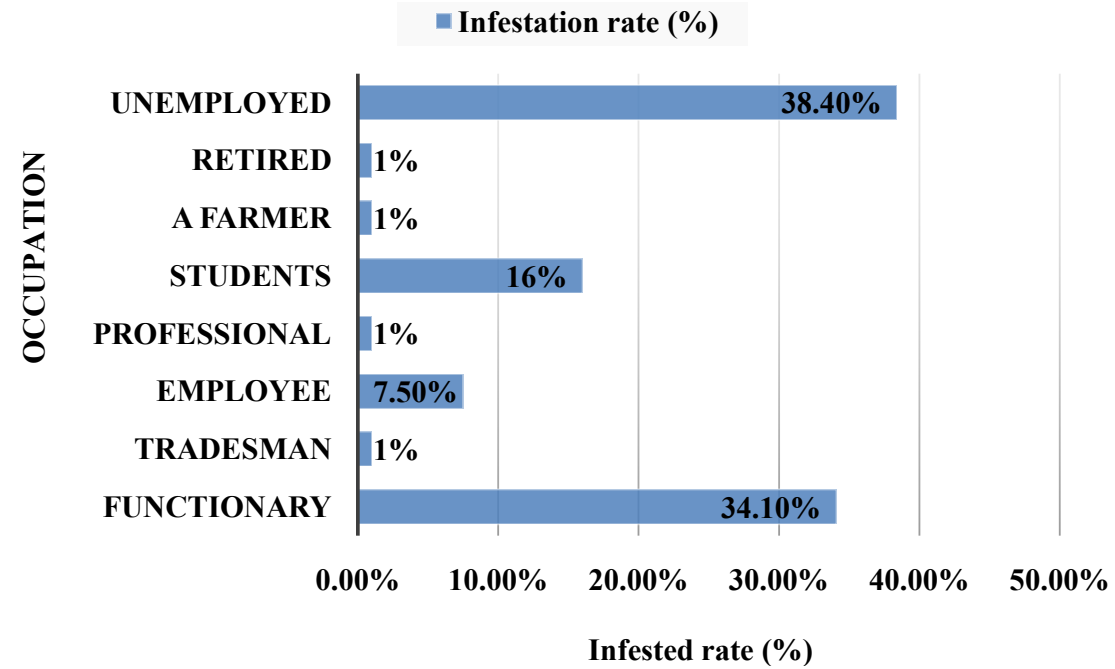

Figure 1. Distribution of TB by occupation. 
for $90 \%$ of cases (Figure 2), further reinforcing TB transmission due to high density [8].

Figure 3 shows a variation in the distribution of the disease according to marital status. Married and single people are the most affected by tuberculosis with rates of $50 \%$ and $43 \%$ respectively. This disease is ubiquitous throughout the province; the city of Kenitra is ranked first, with a $38 \%$, followed by Sidi Yahya (8\%). The disease has concentrated in urban areas and has affected particularly disadvantaged neighborhoods [9].

In the Kenitra area, we find that Moulay Hassan is the area most affected by the disease with $15 \%$ of tuberculosis cases followed by the Saknia area (14\%) and the Bir Rami (12\%) (Figure 4). Tuberculosis remains highly concentrated in very densely populated neighborhoods and in peri-urban areas of large cities, where the influence of socio-economic determinants is most important [4] [10].

\section{Conclusions}

The province of Kenitrais is classified as second on the national level, with Rabat and Salé, as regards the number of tuberculosis cases. It is in this context that our work aims to seek the reasons which caused this classification. To do this, we

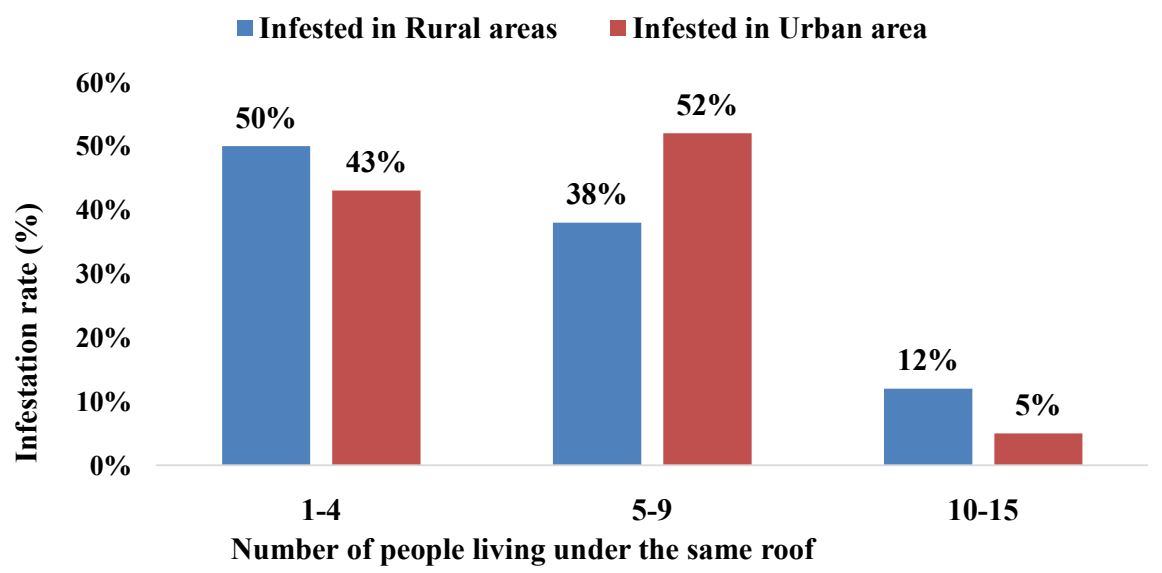

Figure 2. Distribution of TB by number of people living under the same roof.

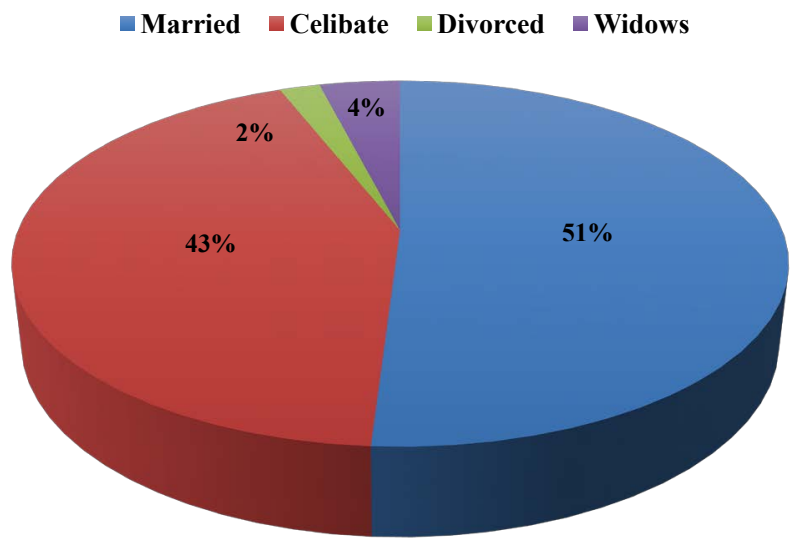

Figure 3. Distribution of TB cases according to marital status. 


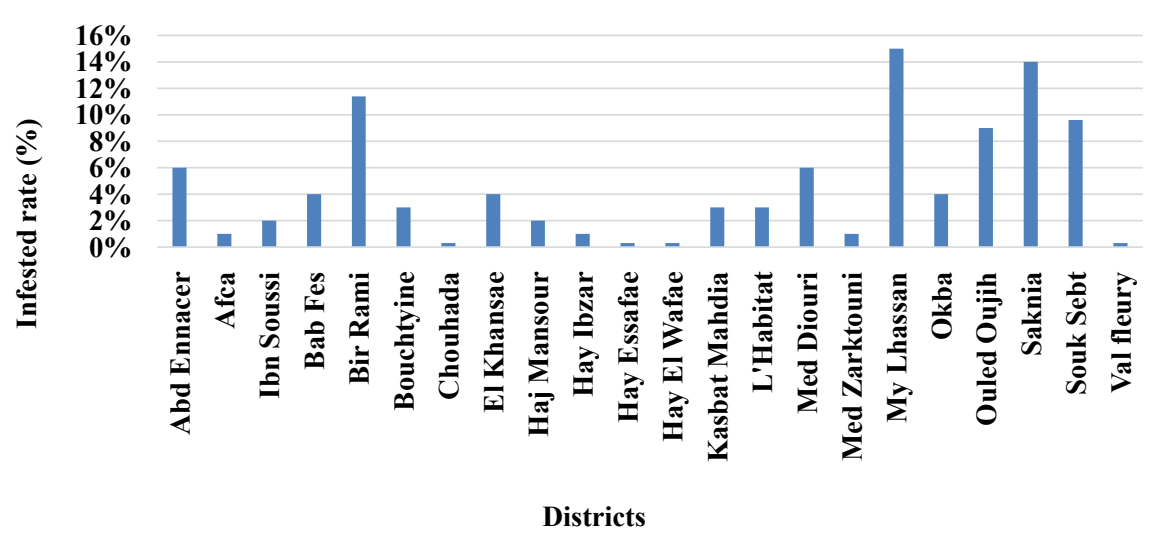

Figure 4. Distribution of tuberculosis cases by district of the Kenitra city.

defined the links between socioeconomic factors and the socio-demographic distribution and spread of the disease. Several studies describing the epidemiological profile of tuberculosis show that the characteristics of TB are similar in most developing countries. Indeed, we find that the age group most affected by this disease is between 15 and 45 years. We also note that TB affects more men than women. We also find that most cases live in urban areas. The present study on tuberculosis in the provincial area of Kenitra for the year 2017, allowed us to note that the incidence of this disease is 94 cases of tuberculosis per 100,000 inhabitants and that the male sex is the most concerned. Following socio-demographic characteristics, linked to the disease as well as the rate of relapses and loss of sight are factors influencing this ranking.

We believe that the health system for the treatment of tuberculosis patients is still to be improved throughout this part of the city of Kenitra in order to hope for a reduction in morbidity and mortality linked to tuberculosis.

\section{Conflicts of Interest}

The authors declare no conflicts of interest regarding the publication of this paper.

\section{References}

[1] WHO (2019) Global Tuberculosis Report.

[2] WHO (2017) Report signals urgent need for greater political commitment to end tuberculosis. 30 October 2017. News Release, Geneva.

[3] Ministère de la santé (2016) Lutte Antituberculeuse au Maroc: progrès, défis et perspectives.

[4] Organisation Mondiale de la santé (2017) Rapport sur la lutte contre la tuberculose dans le monde.

[5] Millet, J.-P., Moreno, A., Fina, L., Del Baño, L., Orcau, A., De Olalla, P.G. andCaylà, J. (2013) Factors That Influence Current Tuberculosis Epidemiology. European Spine Journal, 22, 539-548. https://doi.org/10.1007/s00586-012-2334-8

[6] Organisation Mondiale de la santé (2016) Rapport sur la tuberculose et Appartenance sexuelle. 
[7] Organisation Mondiale de la santé (2011) Rapport sur la lutte contre la tuberculose dans le monde .

[8] Ministère de la santé (2018) Plan stratégique nationale pour la prévention et le contrôle de la tuberculose au Maroc 2012-2018.

https://www.smmg.ma/publications/documents/1-programme-national-de-lutte-co ntre-la-tuberculose/file.html

[9] Ministère de la sante Maroc (2015) Direction de l'épidémiologie et de lutte contre les maladies.

[10] Lönnroth, K., Jaramillo, E., Williams, B.G., Dye, C. and Raviglione, M. (2009) Drivers of Tuberculosis Epidemics: The Role of Risk Factors and Social Determinants. Social Science and Medicine, 68, 2240-2246.

https://doi.org/10.1016/j.socscimed.2009.03.041 